\title{
Effects of increase in organ donation through strengthening of social network service-based communication with medical staff
}

\author{
Hayoung Song, Jaejun Jang, Yangsuk Park, Jeongrim Lee, Insung Moon
}

Korea Organ Donation Agency, Seoul, Korea

Background: Due to the COVID-19 global pandemic in 2020, Korea Organ Donation Agency (KODA) coordinators' visits to hospitals were bound to decrease, thus as a counter measure, a social network service (SNS) has served as a window for the nonface-to-face communication between hospital medical staff and KODA coordinators, thereby sharing the effect.

Methods: Based on the four hospitals that used group chat rooms opened in SNS, this study investigated the number of braindead patients notified to the KODA, the number of contacts with guardians, the number of interviews, the number of completed donation, and the number of KODA coordinator's visits to the hospital retrospectively, from 2019 to 2020.

Results: Compared to 2019, the number of KODA coordinators' visits to four hospitals decreased by about 35\%, from 604 to 393 cases in 2020, and the number of notifications on the patient occurrence brain-dead patients decreased by about $10 \%$, from 200 to 180 cases. In addition, the number of "contact" in which KODA coordinators directly confirm the intention of guardians to interview decreased by about $17.3 \%$, from 122 in 2019 to 101 in 2020. On the other hand, the number of interviews by KODA coordinators with the guardians increased by about 7.6\%, from 66 in 2019 to 71 in 2020, and eventually organ donation increased by about $40.5 \%$, from 32 in 2019 to 45 in 2020.

Conclusions: Despite the difficult times due to the COVID-19 pandemic, a new communication channel called non-face-to-face SNS has been established as an alternative, thereby enabling positive and proactive discussions about the optimal time for both medical staff and KODA coordinators to derive consent from guardians. It is considered that not only the interview rate but also the consent rate for organ donation was raised by conveying accurate information to guardians as a result of this active communication.

Corresponding author: Hayoung Song

E-mail: sgloomy@naver.com

(c) The Korean Society for Transplantation

This is an Open Access article distributed under the terms of the Creative Commons Attribution Non-Commercial License (http://creativecommons.org/licenses/by-nc/4.0/) which permits unrestricted non-commercial use, distribution, and reproduction in any medium, provided the original work is properly cited. 